\title{
Comparison of the effect between pegaptanib and ranibizumab on exudative age-related macular degeneration with small lesion size
}

This article was published in the following Dove Press journal:

Clinical Ophthalmology

3 March 2012

Number of times this article has been viewed

\author{
Yoshihiro Nishimura ${ }^{1,2}$ \\ Maiko Taguchi' \\ Takafumi Nagai' \\ Masashi Fujihara ${ }^{1,2}$ \\ Shigeru Honda ${ }^{2}$ \\ Mamoru Uenishi' \\ 'Department of Ophthalmology, \\ Mitsubishi Kobe Hospital, Kobe, \\ Japan; ${ }^{2}$ Department of Surgery, \\ Division of Ophthalmology, Kobe \\ University Graduate School of \\ Medicine, Kobe, Japan
}

Purpose: To compare the effect of pegaptanib versus ranibizumab on exudative age-related macular degeneration (AMD) with small lesion size.

Methods: This is a retrospective study of 81 eyes from 78 patients with exudative AMD treated and followed up over 12 months. Patients with baseline best corrected visual acuity (BCVA) under 20/400 and with a greatest linear dimension of lesion over $4500 \mu \mathrm{m}$ were excluded from the study. Twenty-six eyes from 25 patients were treated with three consecutive intravitreal injections of pegaptanib (IVP group) and 55 eyes from 54 patients were treated with three consecutive ranibizumab injections (IVR group). Each therapy was repeated as needed. The alteration in BCVA was evaluated in the IVP and IVR groups.

Results: No differences were detected in baseline parameters between the IVP and IVR groups. The mean BCVA (logMAR) at month 1, 3, 6 and 12 after the initial treatment was improved from baseline in the IVP group $(-0.095,-0.17,-0.18$ and -0.18 , respectively) and in the IVR group $(-0.077,-0.15,-0.17$ and -0.11 , respectively), which was statistically significant. There was no difference in the change in mean BCVA between IVP and IVR groups at the same time periods.

Conclusions: The visual outcome of IVP was equivalent with IVR in exudative AMD with small lesion size.

Keywords: pegaptanib, ranibizumab, age-related macular degeneration, small lesion size

\section{Introduction}

Intravitreal injection of anti-vascular endothelial growth factor (VEGF) agent is currently the main treatment for subfoveal choroidal neovascularization (CNV) due to age-related macular degeneration (AMD), a leading cause of central visual loss in the elderly in industrialized countries. ${ }^{1,2}$ Currently, there are two anti-VEGF agents approved to treat exudative (or neovascular) AMD; pegaptanib sodium, a specific antiVEGF $_{165}$ aptamer and ranibizumab, a nonselective anti-VEGF-A antibody. Previous randomized control studies demonstrated a significant improvement in the mean visual acuity of exudative AMD patients treated with intravitreal injection of ranibizumab (IVR), ${ }^{3-5}$ while those treated with intravitreal injection of pegaptanib (IVP) showed no improvement in the mean visual acuity. ${ }^{6}$ However, recent reports documented that visual loss after 24 months of monthly IVR or at 24 months after IVR with a pro re nata (as needed) regimen was associated with abnormalities of retinal pigment epithelium (RPE), excessive subretinal fibrosis, and atrophic scar. ${ }^{7,8}$ We hypothesized that those results might be attributable to nonspecific suppression of VEGF, a potent survival factor for photoreceptor cells, ${ }^{9}$ choroidal vascular endothelial cells, ${ }^{10}$ and $\mathrm{RPE}^{11,12}$
Correspondence: Shigeru Honda Department of Surgery, Division of Ophthalmology, Kobe University Graduate School of Medicine, 7-5-2 Kusunoki-cho, Chuo-ku, Kobe 650-0017, Japan Tel +8I 783826048 Fax +8I 783826059

Email sighonda@med.kobe-u.ac.jp 
thus the subtype-specific anti-VEGF therapy should be selected as the main intervention to treat exudative AMD. To our knowledge, no study has been published to compare the effectiveness between IVP and IVR for exudative AMD with respect to lesion size.

In this study, we performed a comparative assessment to determine whether the visual outcomes of IVP and IVR were different in exudative AMD with relatively smaller lesion size and better baseline visual acuity.

\section{Subjects and methods}

The records of 185 consecutive exudative AMD patients treated by IVP or IVR and followed up over 12 months were retrospectively reviewed. All patients received detailed ophthalmic examinations, including best corrected visual acuity (BCVA) measurements, slit lamp biomicroscopy of their fundi, color fundus photography, fluorescein angiography (FA), indocyanine green angiography (ICG) and optical coherence tomography (OCT). Patients with baseline BCVA under 20/400, those with a greatest linear dimension (GLD) of lesion over $4500 \mu \mathrm{m}$, and patients who had received previous therapy for AMD were excluded from the study. Patients with past histories of retinal vessel occlusion, uveitis, rhegmatogenous retinal detachment or glaucoma were also excluded. Following these protocols, 81 eyes of 78 patients were included for analysis.

From October 2008 to March 2009, all patients were treated by IVP. After ranibizumab became available in Japan (April 2009), IVR was selected as the main intervention and IVP was used for patients with a risk of brain infarction. In the IVP group (26 eyes of 25 patients), all patients received three consecutive IVP injections at 6 weekly intervals as the initial treatment. In the IVR group (55 eyes of 53 patients), all patients received three consecutive monthly IVRs for the initial treatment as previously described. Patients were then followed up with monthly examinations of the lesions ${ }^{13,14}$ and additional IVP or IVR was performed as needed, namely when sustained or recurrent serous retinal detachment, macular edema or hemorrhage was recognized by fundoscopy or OCT. Two patients in the IVP group received IVR 6 months after the initial IVP since the physician considered that IVP was not effective enough to reduce CNV lesions (including serous retinal detachment and macular edema). For those patients, we excluded the data for BCVA at 12 months after the initial treatment from the analysis. However, we counted each IVR as one treatment in the analysis with respect to the number of treatments.
For statistical analysis, we first compared gender, age, BCVA, GLD at baseline between the IVP and IVR groups. Changes in BCVA were then compared until 12 months after the initial treatment. Visual acuities were determined using a Landolt $\mathrm{C}$ chart, and were converted to logarithm of the minimum angle of resolution ( $\log$ MAR) values for calculation. An F-test for homoscedasticity of variance followed by a two-tailed $t$-test or a chi-square test was performed to compare any two groups. $P$ values of 0.05 or less were considered to be statistically significant.

\section{Results}

The data summary of AMD patients treated by IVP or IVR is shown in Table 1. No baseline parameter showed significant difference between the IVP and IVR groups. The F-test indicated homoscedasticity of variance in BCVA between the IVP and IVR groups $(\mathrm{F}$-value $=0.49, P=0.49)$. In the time course analysis, the mean BCVA was significantly improved compared with the baseline BCVA in each group (Figure 1). Although the IVR group showed a decrease in the mean BCVA at the 12 month follow-up, there was no significant difference between the IVP group and the IVR group at any time period measured. For BCVA measurements, about $25 \%-30 \%$ of patients gained more than 0.3 LogMAR during 12 months after the initial therapy, whereas about $10 \%$ of patients lost more than 0.3 LogMAR during the same time period in both groups (Figure 2). There was no significant difference in the proportion of BCVA change in the IVP

Table I Data summary of the participants treated by intravitreal injection of pegaptanib or ranibizumab

\begin{tabular}{llll}
\hline & IVP $(\mathbf{n}=\mathbf{2 6})$ & IVR $(\mathbf{n}=\mathbf{5 5})$ & $\mathbf{P}$ value \\
\hline Male/female & $19 / 6$ & $35 / 18$ & $0.37^{\dagger}$ \\
Age (years) & $72.2 \pm 11.0$ & $74.3 \pm 9.7$ & $0.40^{*}$ \\
Age range (years) & $50-89$ & $51-92$ & \\
$\begin{array}{l}\text { Lesion type (eyes) } \\
\text { Predominantly classic }\end{array}$ & 6 & 8 & \\
Minimally classic & 6 & $\mathrm{II}$ & $0.65^{\dagger}$ \\
Occult with no classic & 4 & 14 & \\
With PCV & 10 & 22 & \\
Baseline BCVA (LogMAR) & $0.44 \pm 0.37$ & $0.50 \pm 0.36$ & $0.49 *$ \\
BCVA range & $20 / 400-20 / 20$ & $20 / 400-20 / 20$ & \\
Baseline GLD ( $\mu \mathrm{m})$ & $2337 \pm 1014$ & $2825 \pm 912$ & $0.10^{*}$ \\
GLD range $(\mu \mathrm{m})$ & $686-4290$ & $810-4232$ & \\
Number of injections/year & $4.6 \pm 2.2$ & $5.1 \pm 2.3$ & $0.39 *$ \\
Number of injections/year & $3-9$ & $3-11$ & \\
range & & & \\
\hline
\end{tabular}

Notes: Values are presented as mean $\pm \mathrm{SD}$ when applicable. *Unpaired $t$-test; ${ }^{\dagger}$ chi-square test.

Abbreviations: IVP, intravitreal injection of pegaptanib; IVR, intravitreal injection of ranibizumab; BCVA, best corrected visual acuity; GLD, greatest linear dimension; PCV, polyploidal choroidal vasculopathy. 


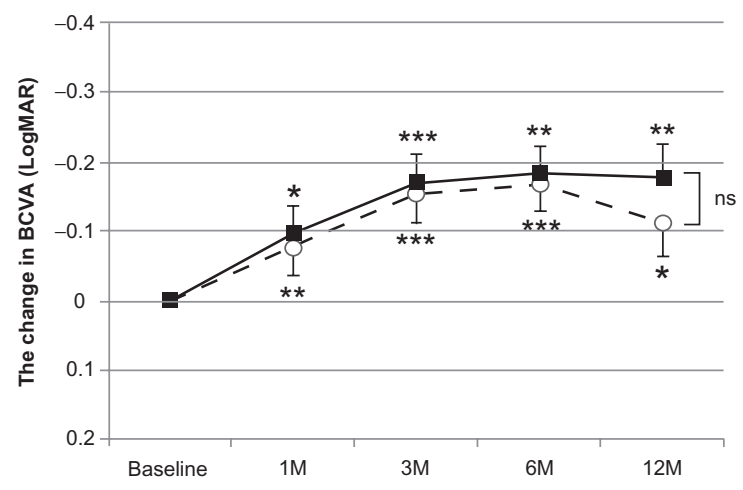

Figure I Changes in the best corrected visual acuity (BCVA) after intravitreal pegaptanib or ranibizumab.

Notes: Squares with solid lines: pegaptanib; Circles with dashed lines: ranibizumab. Values represent means \pm standard error in the mean. $* P<0.05 ; * * P<0.005$; $* * * P<0.0005$ compared to baseline.

Abbreviation: ns, not significant.

group versus the IVR group $(P=0.68)$. An accumulation of subfoveal hard exudates was found in one case in the IVP group, whereas four cases showed atrophic scars and three cases showed subfoveal fibrosis in the IVR group, and those were associated with a deterioration of BCVA 12 months after the initial treatment.

\section{Discussion}

We compared the effect of IVP versus IVR on exudative AMD with relatively small lesion size, and demonstrated that the visual outcome was not significantly different between the IVP and IVR groups. In other words, IVP was a good modality of choice for exudative AMD without severe visual disturbance and with smaller GLD at baseline.

Currently, anti-VEGF therapies are the leading modalities for exudative AMD. ${ }^{15-17}$ Many reports demonstrated that IVR remarkably attenuated the activity of CNV and improved the average visual outcome. However, recent reports have shown

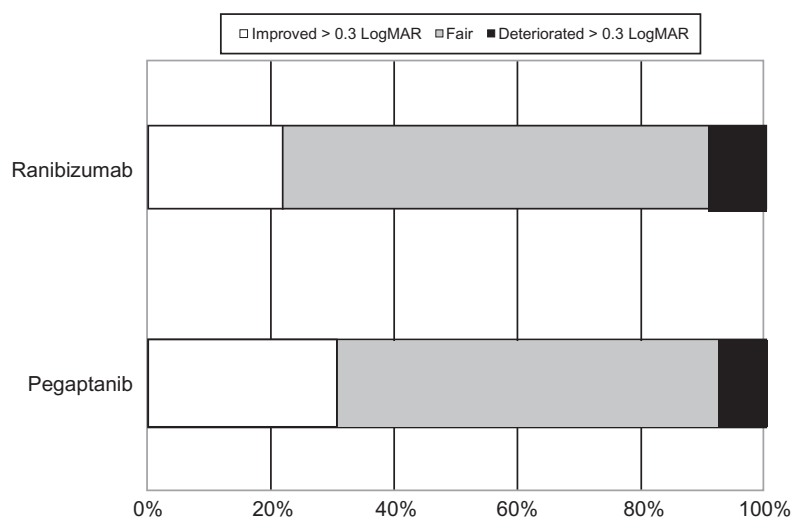

Figure 2 Proportion of the change in the BCVA (LogMAR) between baseline and after 12 months of intravitreal pegaptanib or ranibizumab in the exudative AMD patients. that secondary visual loss, occurring at or after month 24 of IVR, was associated with abnormalities of the retinal pigment epithelium (RPE), subretinal fibrosis and atrophic scar, ${ }^{7,8}$ which suggested the risk of nonspecific suppression of VEGF by ranibizumab. Efforts were made to decrease the number of IVR injections to treat exudative AMD, ${ }^{5,13,14}$ but the use of IVP may be considered as an alternative therapy for exudative AMD with small lesion size. ${ }^{18} \mathrm{VEGF}_{165}$ is known as the major inducer of abnormal blood vessel growth and leakage in wet AMD, ${ }^{19,20}$ but all VEGF-A isoforms are key angiogenic and neuroprotective factors for several tissues..$^{9-12,21-23}$ Nonspecific inhibition of all VEGF-A isoforms might reduce the ability to tolerate several kind of stresses in the photoreceptor, RPE and normal choroidal endothelial cells. The abnormalities of RPE and atrophic scars found in the cases treated with monthly IVR might reflect the lack of VEGF-mediated neuroprotection for the cells. Interestingly, we found that four cases showed atrophic scars and three cases showed subfoveal fibrosis in the IVR group while these findings were not observed in the IVP group in the present study. To avoid the risk of oversuppression of physiological VEGF effects, many studies have been conducted to reduce the number of IVR injections. ${ }^{5,13,14} \mathrm{~A}$ recent prospective study has demonstrated good visual outcomes of exudative AMD patients by using IVP as a maintenance therapy after IVR. ${ }^{24}$ Other studies reported that good visual stability was obtained with IVP monotherapy in selective cases, particularly those in the early stage. ${ }^{25,26}$ Since the pathogenesis of CNV is thought to be associated with $\mathrm{VEGF}_{165}$ and $\mathrm{VEGF}_{121}{ }^{27,28}$ IVP monotherapy may not be sufficient to suppress all CNV. However, our results have demonstrated that IVP could be a useful modality of choice for the patients with exudative AMD having small lesion size.

The major limitation of the present study was the nonrandomized and retrospective nature of the study and the relatively small number of subjects. Hence, it is important to evaluate the results of randomized control trials for IVP and IVR with a large number of subjects to determine the comparative effectiveness of these therapies, particularly for exudative AMD with small lesion size. Further investigations will be needed to determine the correct indications for use of IVP and IVR for exudative AMD.

In conclusion, IVP may be an effective therapy for BCVA over a 12 month period in patients with exudative AMD and lesions less than $4500 \mu \mathrm{m}$ in size.

\section{Acknowledgments}

This study was supported by Grant-in-Aid (C) 23592567 from the Ministry of Education, Science, and Culture, 
Tokyo, Japan (S.H.), and by a grant from the Takeda Science Foundation (S.H.). The funding organizations had no role in the design or conduct of this research.

\section{Disclosure}

The authors report no conflicts of interest in this work.

\section{References}

1. Hernandez-Pastor LJ, Ortega A, Garcia-Layana A, Giraldez J. Ranibizumab for neovascular age-related macular degeneration. Am J Health Syst Pharm. 2008;65(19):1805-1814.

2. Morris B, Imrie F, Armbrecht AM, Dhillon B. Age-related macular degeneration and recent developments: new hope for old eyes? Postgrad Med J. 2007;83(979):301-307.

3. Rosenfeld PJ, Brown DM, Heier JS, et al. MARINA Study Group. Ranibizumab for neovascular age-related macular degeneration. NEngl $J$ Med. 2006;355(14):1419-1431.

4. Brown DM, Michels M, Kaiser PK, Heier JS, Sy JP, Ianchulev T. ANCHOR Study Group. Ranibizumab versus verteporfin photodynamic therapy for neovascular age-related macular degeneration: two-year results of the ANCHOR study. Ophthalmology. 2009;116(1):57-65.

5. Mitchell P, Korobelnik JF, Lanzetta P, et al. Ranibizumab (Lucentis) in neovascular age-related macular degeneration: evidence from clinical trials. Br J Ophthalmol. 2010;94(1):2-13.

6. Gonzales CR. VEGF Inhibition Study in Ocular Neovascularization (V.I.S.I.O.N.) Clinical Trial Group. Enhanced efficacy associated with early treatment of neovascular age-related macular degeneration with pegaptanib sodium: an exploratory analysis. Retina. 2005;25(7):815-827.

7. Rosenfeld PJ, Shapiro H, Tuomi L, Webster M, Elledge J, Blodi B; MARINA and ANCHOR Study Groups. Characteristics of patients losing vision after 2 years of monthly dosing in the phase III ranibizumab clinical trials. Ophthalmology. 2011;118(3):523-530.

8. Mariani A, Deli A, Ambresin A, Mantel I. Characteristics of eyes with secondary loss of visual acuity receiving variable dosing ranibizumab for neovascular age-related macular degeneration. Graefes Arch Clin Exp Ophthalmol. 2011;249(11):1635-1642.

9. Englund-Johansson U, Mohlin C, Liljekvist-Soltic I, Ekström P, Johansson K. Human neural progenitor cells promote photoreceptor survival in retinal explants. Exp Eye Res. 2010;90(2):292-299.

10. Gerber HP, McMurtrey A, Kowalski J, et al. Vascular endothelial growth factor regulates endothelial cell survival through the phosphatidylinositol 3'-kinase/Akt signal transduction pathway. Requirement for Flk-1/KDR activation. J Biol Chem. 1998;273(46):30336-30343.

11. Ford KM, Saint-Geniez M, Walshe T, Zahr A, D'Amore PA. Expression and role of VEGF in the adult retinal pigment epithelium. Invest Ophthalmol Vis Sci. 2011;52(13):9478-9487.

12. Byeon SH, Lee SC, Choi SH, et al. Vascular endothelial growth factor as an autocrine survival factor for retinal pigment epithelial cells under oxidative stress via the VEGF-R2/PI3K/Akt. Invest Ophthalmol Vis Sci. 2010;51(12):1190-1197.

13. Fung AE, Lalwani GA, Rosenfeld PJ, et al. An optical coherence tomography-guided, variable dosing regimen with intravitreal ranibizumab (Lucentis) for neovascular age-related macular degeneration. Am J Ophthalmol. 2007;143(4):566-583.

Clinical Ophthalmology

\section{Publish your work in this journal}

Clinical Ophthalmology is an international, peer-reviewed journal covering all subspecialties within ophthalmology. Key topics include: Optometry; Visual science; Pharmacology and drug therapy in eye diseases; Basic Sciences; Primary and Secondary eye care; Patient Safety and Quality of Care Improvements. This journal is indexed on Submit your manuscript here: http://www.dovepress.com/clinical-ophthalmology-journal
14. Lalwani GA, Rosenfeld PJ, Fung AE, et al. A variable-dosing regimen with intravitreal ranibizumab for neovascular age-related macular degeneration: year 2 of the PrONTO Study. Am J Ophthalmol. 2009;148(1):43-58.

15 Schmidt-Erfurth UM, Richard G, Augustin A, et al. European Society for Retina Specialists' Guidelines Committee (EURETINA): Guidance for the treatment of neovascular age-related macular degeneration. Acta Ophthalmol Scand. 2007;85(5):486-494.

16. Ip MS, Scott IU, Brown GC, et al. Anti-vascular endothelial growth factor pharmacotherapy for age-related macular degeneration: a report by the American Academy of Ophthalmology. Ophthalmology. 2008;115(10):1837-1846.

17. Mekjavic PJ, Kraut A, Urbancic M, Lenassi E, Hawlina M. Efficacy of 12-month treatment of neovascular age-related macular degeneration with intravitreal bevacizumab based on individually determined injection strategies after three consecutive monthly injections. Acta Ophthalmol. 2011;89(7):647-653.

18. Rosina C, Bottoni F, Staurenghi G. Clinical experience with pegaptanib sodium. Clin Ophthalmol. 2008;2(3):485-488.

19. Mader JS, Smyth D, Marshall J, Hoskin DW. Bovine lactoferricin inhibits basic fibroblast growth factor- and vascular endothelial growth factor 165 -induced angiogenesis by competing for heparin-like binding sites on endothelial cells. Am J Pathol. 2006;169(5):1753-1766.

20. Vinores SA. Pegaptanib in the treatment of wet, age-related macular degeneration. Int J Nanomedicine. 2006;1(3):263-268.

21. Van de Veire S, Van Bergen T, Vandewalle E, Carmeliet P, Moons L, Stalmans I. The role of the VEGF-isoforms in pathological choroidal/ retinal angiogenesis. Bull Soc Belge Ophtalmol. 2011;317:55.

22. Manoonkitiwongsa PS. Critical questions for preclinical trials on safety and efficacy of vascular endothelial growth factor-based therapeutic angiogenesis for ischemic stroke. CNS Neurol Disord Drug Targets. 2011;10(2):215-234.

23 Kim I, Ryan AM, Rohan R, et al. Constitutive expression of VEGF, VEGFR-1, and VEGFR-2 in normal eyes. Invest Ophthalmol Vis Sci. 1999;40(9):2115-2121.

24. Friberg TR, Tolentino M; LEVEL Study Group, Weber P, Patel S, Campbell S, Goldbaum M. Pegaptanib sodium as maintenance therapy in neovascular age-related macular degeneration: the LEVEL study. $\mathrm{Br}$ J Ophthalmol. 2010;94(12):1611-1617.

25. Ricci F, Missiroli F, Cedrone C, Grossi M, Regine F. Compassionate use of intravitreal pegaptanib in patients with age-related macular degeneration. Semin Ophthalmol. 2010;25(1-2):16-20.

26. Weber PA, Wirostko BM, Xu X, Goss TF, Zlateva G. Newly diagnosed exudative age-related macular degeneration treated with pegaptanib sodium monotherapy in US community-based practices: medical chart review study. BMC Ophthalmol. 2010;10:2.

27. Bhisitkul RB. Vascular endothelial growth factor biology: clinical implications for ocular treatments. $\mathrm{Br} J$ Ophthalmol. 2006;90(12):1542-1547.

28. Rakic JM, Lambert V, Devy L, et al. Placental growth factor, a member of the VEGF family, contributes to the development of choroidal neovascularization. Invest Ophthalmol Vis Sci. 2003;44(7):3186-3193.

\section{Dovepress}

PubMed Central and CAS, and is the official journal of The Society of Clinical Ophthalmology (SCO). The manuscript management system is completely online and includes a very quick and fair peer-review system, which is all easy to use. Visit http://www.dovepress.com/ testimonials.php to read real quotes from published authors. 